\title{
1D-2D Hydrodynamic Model Coupling for Inundation Analysis of Sewer Overflow
}

\author{
${ }^{1}$ A.G. Adeogun, ${ }^{2}$ A. Pathirana and ${ }^{3}$ M.O. Daramola \\ ${ }^{1}$ National Center for Hydropower Research and Development, \\ University of Ilorin, P.M.B. 1515, Ilorin, Nigeria \\ ${ }^{2}$ UNESCO-IHE Institute for Water Education, P.O. Box 3015, 2601 DA Delft, The Netherlands \\ ${ }^{3}$ Department of Chemical Engineering, Obafemi Awolowo University, Ile-Ife, Nigeria
}

\begin{abstract}
In order to enable estimation of flood damage due to sewer overflow, a Sewer Network Model (SWMM) was coupled with an Inundation Model (BreZo) based on irregular triangular meshes. SWMM uses a 1D explicit finite difference solver that handles the full shallow water equations. BreZo employs a Godunovtype finite volume algorithm to explicitly solve the shallow water equations. The model coupling was effected by transferring mass (and neglecting momentum) from the Sewer Network Model to the Inundation Model. The flow back into the sewer network during the recession hydrograph from the surface was not considered. The model was evaluated by applying it to a case study taken from the urban drainage system in West Garforth, UK. The model application showed that computational economy was achieved. Also, the coupled model performed well against stability and mass balance criteria.
\end{abstract}

Key words: Urban flood, inundation, model coupling, triangular grid, urban drainage, Nigeria

\section{INTRODUCTION}

Sewer overflow due to inadequate hydraulic capacity is a major cause of intra-urban flooding. This type of flooding can cause significant economic damage as well as nuisance to society. Urban drainage models are necessary to estimate the extent of damages as a result sewer overflow. Many urban drainage models are essentially one dimensional network abstraction models. These are quite efficient in modeling large sewer networks but are only capable of providing flood volumes in the case of sewer overflow. The urban topography is generally too complex and surface flow processes too dynamic for distributing these overflow volumes with simple terrain-filling schemes. Using dynamical inundation models is therefore considered advantageous for flood damage estimation.

Most inundation models are designed to be used for large floods associated with events such as fluvial flooding and often do not have the same capability as network models to represent one-dimensional network flow (e.g., in closed conduits). An efficient and accurate approach to estimate flood characteristics and damage due to sewer overflow is to couple network models with inundation models (1D-2D coupling). Often modifications are needed in the inundation models to be efficiently adopted as candidates for 1D-2D coupling for urban flood modeling. Besides that many of these models are time consuming in their approach to simulating and predicting the inundation extent, depth and velocity. However, a simple and quick prediction of flooding within acceptable limits is sometimes more important than running an accurate (but) time-consuming Hydrodynamic Model simulation. This balance between computational time and accuracy needs careful consideration. A typical situation where computational efficiency becomes important is using models for optimization studies where thousands of model runs are required in the optimization process. In fact, one of the objectives of this study was to provide an adequate coupled model for multi-objective optimization. A coupled 1D-2D Hydrodynamic Model is developed taking into consideration the exchange of conservation quantities. This tool is assembled from components taken from two existing models, the $1 \mathrm{D}, \mathrm{SWMM}$ and the $2 \mathrm{D}$ Hydrodynamic Model, BreZo (Begnudelli and Sanders, 2006). Because both simulation models employ explicit solvers, the computational burden is not excessive. This is expected to result in affordable simulation times.

\section{MATERIALS AND METHODS}

Model formulation and development
Model selection: Due to its simplicity and open source
code, EPA-SWMM developed under the support of

Corresponding Author: A.G. Adeogun, National Center for Hydropower Research and Development, University of Ilorin, P.M.B. 1515, Ilorin, Nigeria 
US-EPA was selected to model the surcharges due to sewer overflow in urban areas. The modeling of the two-Dimensional (2D) part was done using BreZo. The two models use explicit scheme which is more economical in terms of computational efficiency, especially in urban drainage analysis. BreZo employs the use of finite volume scheme (ensuring excellent mass conservation) based on triangular cells which work on unstructured grids, thus allowing an increased geometrical flexibility.

1D Storm Water Management Model (SWMM): SWMM is a dynamic Rainfall-runoff Simulation Model used for single event or long-term (continuous) simulation of runoff quantity and quality from primarily urban areas. SWMM is made up of runoff block which can be used to operate on a collection of sub-catchment areas that receive precipitation and generate runoff and pollutant loads. The runoff block calculates runoff discharge on rainfall system. The routing portion of SWMM is responsible for transporting this runoff through a system of pipes, channels, storage/treatment devices, pumps and regulators. The amount of surcharge flow from the manholes in a sewer network to the surface is given by the equation:

$$
Q_{s}=Q_{\text {in }}-Q_{f}
$$

Where:

$\mathrm{Q}_{\text {in }}=$ The total inflow as discharge from the upstream conduit

$\mathrm{Q}_{\mathrm{f}}=$ The design full capacity of the downstream conduit and $Q_{f}$ defined as:

$$
\mathrm{Q}_{\mathrm{f}}=\frac{1}{\mathrm{n}_{\mathrm{c}}} \mathrm{A}_{\mathrm{f}} \mathrm{R}_{\mathrm{f}}^{2 / 3} \mathrm{~S}_{\mathrm{f}}^{1 / 2}
$$

Where:

$\mathrm{n}_{\mathrm{c}}=$ The Manning's roughness of the conduit

$\mathrm{A}_{\mathrm{f}}=$ The full cross sectional area of the conduit $\mathrm{R}$, the hydraulic radius for full flow

$\mathrm{S}_{\mathrm{f}}=$ Friction slope of conduit

Surcharge occurs when $Q_{n}>Q_{f}$ and the rest of the flow surcharges through the manhole causing inundation of the flood plain. At each of the surcharged manhole, SWWM can be used to produce hydrographs which eventually serve as input for the 2D Hydrodynamic Model to determine the inundation zones and depth and velocities.

2D Hydrodynamic Model (BreZo): BreZo is an efficient Hydrodynamic Model developed for unsteady, two dimensional, shallow water flow over an arbitrary topography with wetting and drying (Begnudelli and
Sanders, 2006). The model employs a novel scheme to improve accuracy by choosing variables for reconstruction at cell faces (required for application of approximate Riemann solver) according to the local froude number and a new local time-stepping scheme that improves run-time efficiency while maintaining stability. The shallow water equations were solved using a Godunov-type finite volume algorithm on unstructured grids of triangular cells. The model handles drying and wetting conditions successfully. It reads the file format and file naming conventions used by Triangle, a 2D mesh generator developed by Shewchuk (1996).

Governing equations: The governing equations used in BreZo are the fluid continuity equation and two momentum equations which are solved using finite volume method through the application of integral law on the discretized computational domain. These equations, also known as shallow water equations are presented as:

$$
\frac{\partial}{\partial \mathrm{t}} \int_{\Omega} \mathrm{Ud} \Omega+\oint_{\mathrm{d} \Omega}(\mathrm{Fdx}-\mathrm{Gdy})=\int_{\Omega} \mathrm{Sd} \Omega
$$

Where the computational domain is represented as $\Omega$ with a boundary $\mathrm{d} \Omega$. U, F and $\mathrm{G}$ are the vectors of flow variable, the flux term and the source terms and they are represented as follows:

$$
\mathrm{U}=(\mathrm{h}, \mathrm{uh}, \mathrm{vh})^{\mathrm{T}}
$$

$$
F=\left[\begin{array}{l}
u h \\
u^{2} h+\frac{1}{2} g h^{2} \\
u v h
\end{array}\right]
$$

$$
\mathrm{G}=\left[\begin{array}{l}
\mathrm{Vh} \\
\mathrm{uvh} \\
\mathrm{v}^{2} \mathrm{~h}+\frac{1}{2} \mathrm{gh}^{2}
\end{array}\right]
$$

Where:

$$
S=\left[\begin{array}{l}
0 \\
-g h \frac{\partial z_{b}}{\partial x}-c_{D} u \sqrt{u^{2}+v^{2}} \\
-g h \frac{\partial z_{b}}{\partial y}-c_{D} u \sqrt{u^{2}+v^{2}}
\end{array}\right]
$$

$\mu$ and $v=$ The depth average flow velocities in the $\mathrm{x}, \mathrm{y}$ directions, respectively 
$Z_{b}=$ The bed elevation

$C_{D}=$ The bed drag coefficient which can be computed from Manning's coefficient $n_{M}$ as follows:

$$
c_{D}=g_{M}^{2} h^{-1 / 3}
$$

\section{MODEL COUPLING TECHNIQUES}

Interacting quantities: In this tool, the surcharged overflow is taken as the interacting physical process between the two models. The other conservation quantity, momentum does not have significant contribution to proper coupling, in the case of sewer overflow. This is because the lateral velocity of the water overflowing from the sewer network to the surface system is very small compared to other terms in the momentum equation. At manholes where there are sewer surcharges, runoff is allowed from the sewer to the overland surface (Fig. 1). In this case, the water depth above ground level as provided by SWMM is used as input in the 2D Hydrodynamic Model BreZo in the each subsequent time step.

Coupled model algorithm: The algorithm for the new tool is a modified version of the algorithm presented by Pathirana et al. (2008) and it is shown in Fig. 2. The modified algorithm was implemented with a computer code written in $\mathrm{C}++$ programming language. In writing the source code for the model, the following steps were incorporated:

- The two models 1D-SWWM and 2D-BreZo were initialized at the start of the computation

- One of the coupler functions receives overflow discharge from the manholes of the sewer network and transforms it into a flow rate per unit grid cell area within the computational domain

- At the end of each reporting time step of SWMM, the result is passed to the $2 \mathrm{D}$ part for routing. The interaction is done in such a way that BreZo steps a number of times for every reporting time step in SWWM. For example, if the reporting time step is $5 \mathrm{~min}$, the time step in BreZo can be set at $0.5 \mathrm{sec}$ (dt) and number of time steps (nt) at 600

- The simulation stops when the elapsed time in SWMM is greater than or equal to the total sum of the reporting time steps

- At each reporting time step in SWMM, a restart file is created in the $2 \mathrm{D}$ part. This restart file contains the current values for water level, velocities ( $u$ and v), maximum observed velocities and maximum observed water level. However, this depends on the options

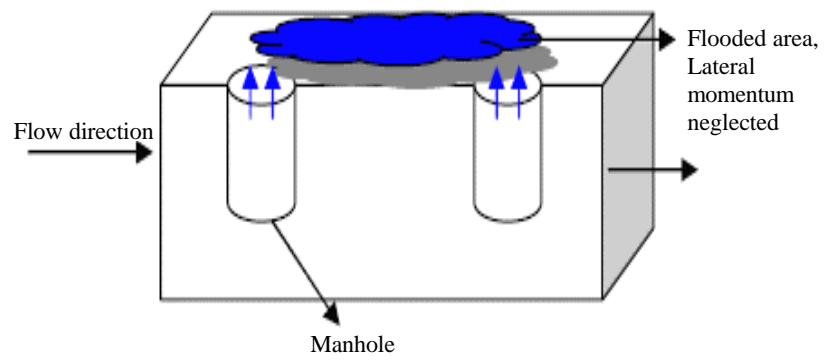

Fig. 1: Schematic representation of what happens at the manholes (momentum transfer in lateral direction neglected)

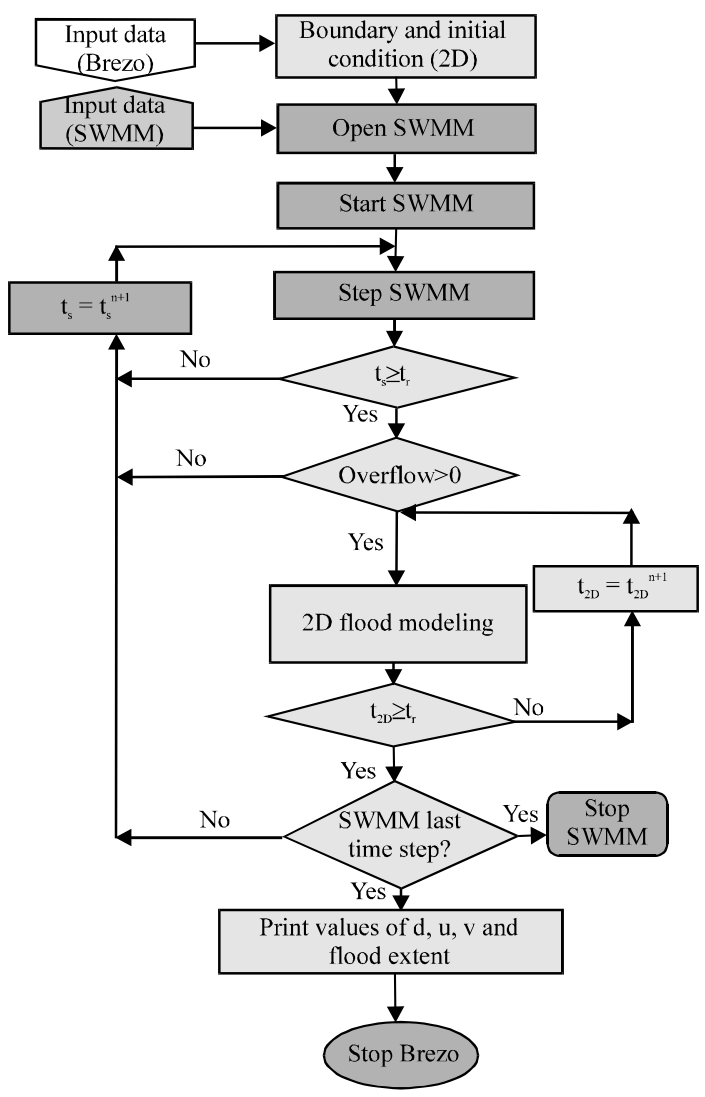

Fig. 2: Coupled Model Algorithm

used in the input file of BreZo. To create a restart file, the initial condition option has to be specified to read from the restart file while the maxflood option has to be turned on. The use of the restart file helps in improving the quality of the model result by making it possible to re-start a simulation and continue the maximum flood (velocities, height) calculations from the previous run.

\section{MODEL APPLICATION}

The coupled model was applied to a case study area in the city of West Garforth, New Yorkshire (UK). 


\section{J. Eng. Applied Sci., 7 (5): 356-362, 2012}

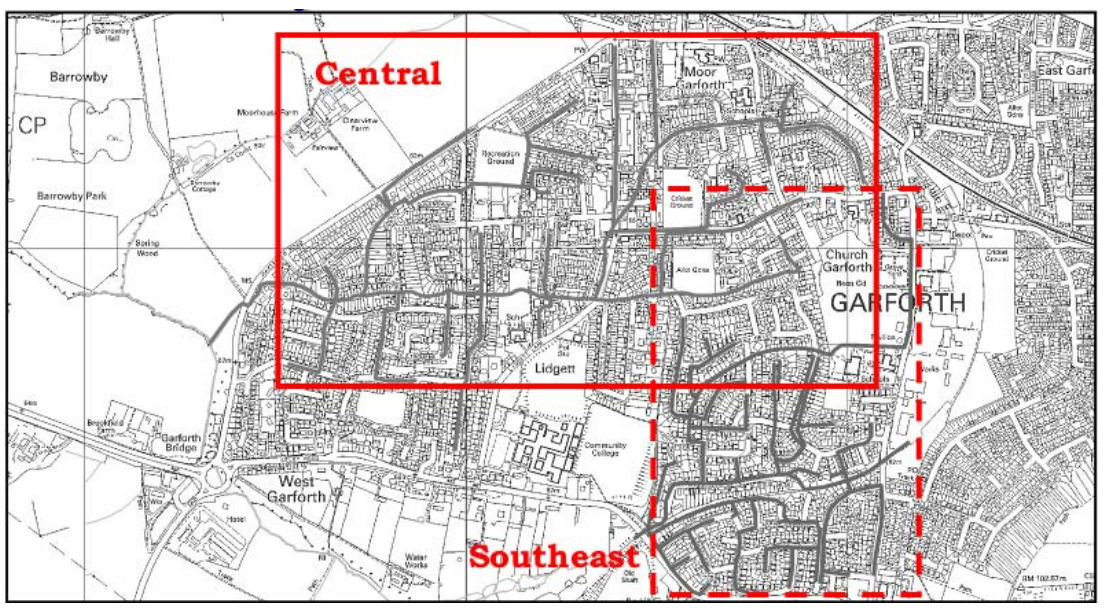

Fig. 3: Catchment divisions in the study area

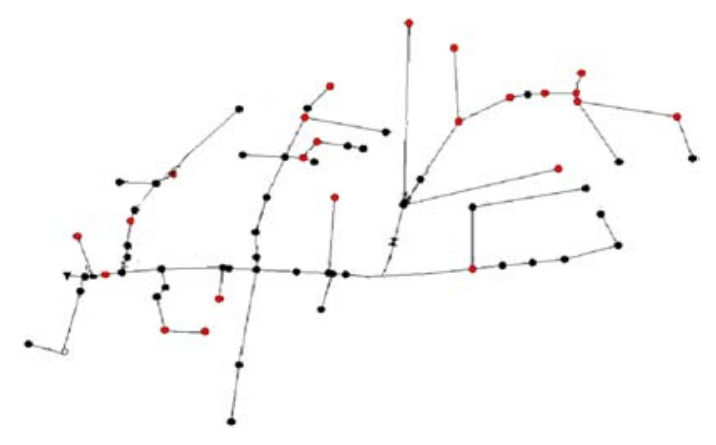

Fig. 4: Drainage network of the Central Model in the Northern region

Flooding at this site is reported to have been caused mainly by surcharged overflow due to inadequate hydraulic capacity of the existing drainage system.

Description of case study area: The case study area was taken from the city of West Garforth, UK. The area is divided into two catchments namely, the Northern and the Southern area. Figure 3 shows the division of the area into two catchments. Previous studies carried out by PWG (2007) in collaboration with Yorkshire Water Services (YWS) and the Environmental Agency (EA) resulted in the development of the model for both drainage systems, namely the Central Model in the Northern region and the Southeast Model in the Southeast region. For the purpose of this study, only the central model drainage network was used. Figure 4 shows the drainage network of the Central Model.

\section{Model input parameters}

Rainfall: For the sewer network modeling, a rainfall hyetograph is required as input time series. The hyetograph for West Garforth was generated with UK Rainfall Generator which is based on the Flood Studies Report and updated by FEH (1999). Total depth of rainfall for the 30 years $90 \mathrm{~min}$ design storm is $29.62 \mathrm{~mm}$.

Sewer network data: The sewer network data were obtained from both the sewer asset database and the hydraulic investigation that was part of the Integrated Urban Drainage Pilot Study (DEFRA, 2008).

Topographical data: For the inundation modeling, topographical data is needed. A contour map of West Garforth was generated on the basis of the GPS survey data provided by the EA. The GPS data had been collected by driving a car along the streets in the study area with a GPS device. ArcGIS was used to develop the Digital Elevation Model (DEM) of the study area, incorporating roads and building features. The DEM generated from ArcGIS was triangulated and other required files were produced using the Triangle software and Gaja3D developed by Shewchuk (1996), respectively. The resolution of the DEM was set at $4 \mathrm{~m}$. Figure 5 shows the 3D Digital Elevation Model of the West Garforth case study area. The surface area of the Central Model is estimated to be around 140 ha. This is triangulated into 176,180 cells. The required files for the $2 \mathrm{D}$ part of the coupled model were produced as part of the triangulation.

Initial and boundary conditions: In order to solve the shallow-water equations, the initial conditions had to be specified which consisted of the spatial distribution of water level $(\eta)$ or depth (h) as well as velocity ( $u$ and v). This was done in 2D Hydrodynamic Model, BreZo using the input files. The following initial and boundary conditions were set in the input file of the 2D Model: 


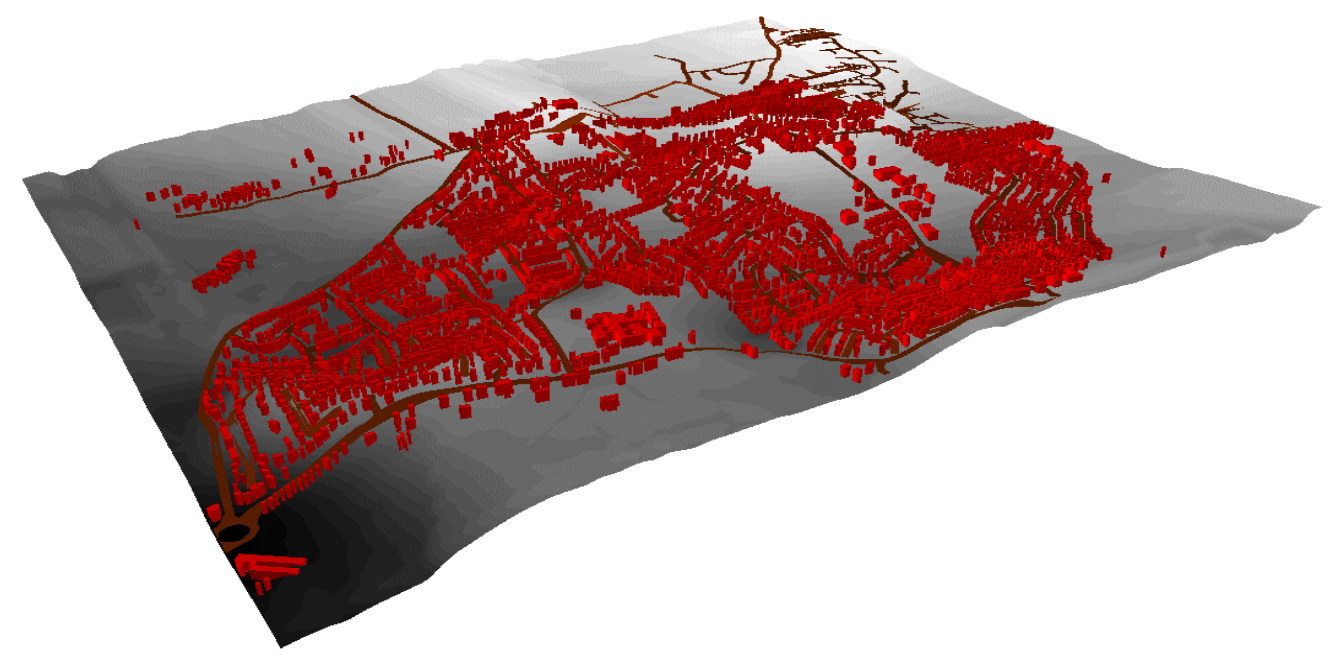

Fig. 5: DEM of West Garforth, attributed with roads and buildings

- A uniform value of 0.00 was assigned to velocity components ( $\mathrm{u}$ and $\mathrm{v}$ ) and 0.0001 for water depth (h). This is to prevent model instability which might result from completely dry cells at the start of the simulation

- Velocity components of the boundary cells were taken as zero value for each time step of simulation

- The option to use a restart file was chosen in the input file. At the end of each routing step of BreZo, a restart file is then created which states the current values of velocities in both directions and the flood depth. This is used for the next time step of SWWM

- On the boundary along the periphery of the area, the inflow was set to zero. This is done by using a boundary condition file (bc file) and set the type as wall. This prevents the contribution of cells outside the boundary domain in the computation

Roughness data: Roughness data are needed for the topographical terrain of the study area. A uniform value of 0.02 was adopted and Manning's formula is used for the computation of the friction terms in the shallow water equations.

Courant condition: The stability of the 2D Model is determined by Courant-Friedrichs-Levy (CFL) condition (Begnudelli and Sanders, 2006). For the explicit finite volume scheme as used in BreZo, the time step used is calculated from the following expression (Sanders, 2008):

$$
\mathrm{Cr}=\Delta \operatorname{tmax}_{\mathrm{i}=1, \ldots, \mathrm{N}_{\mathrm{C}}}\left\{\frac{3 \max _{\mathrm{k}=1,2,3}\left|\lambda \frac{1}{\mathrm{f}_{\mathrm{i}, \mathrm{k}}^{\mathrm{c}}} 1 \mathrm{f}_{\mathrm{i}, \mathrm{k}}^{\mathrm{c}}\right|}{\mathrm{A}_{\mathrm{I}}}\right\} \leq 1
$$

Where:

$$
\begin{aligned}
\mathrm{i} & =1, \ldots, \mathrm{N}_{\mathrm{c}} \\
\mathrm{Cr} & =\text { The courant number } \\
\Delta \mathrm{t} & =\text { Time step } \\
\lambda \frac{1}{\mathbf{f}_{\mathrm{i}, \mathrm{k}}^{\mathrm{c}}} \mathbf{f}_{\mathrm{j}, \mathrm{c}}^{\mathrm{c}} & =\text { The wave speed normal to the kth face of the } \\
& \text { ith cell }
\end{aligned}
$$

For this case study, the model was run with a constant time step of $0.5 \mathrm{sec}$ which is within the acceptable limit of what courant number dictates.

\section{RESULTS AND DISCUSSION}

Surcharge of manholes: The surcharge flow occurred at different times and locations in total 28 nodes were flooded and the total flood volume in the computational domain is estimated to be $4,915 \mathrm{~m}^{3}$. The $2 \mathrm{D}$ Hydrodynamic Surface Flow Model provides the potentially inundated areas and it illustrates the flood routes. Using Tecplot Visualization Software, the flood area is calculated per specified monitoring time interval. A brief summary of the model result is as shown in Table 1. The total model run time for a simulation time period of $5 \mathrm{~h}$ is quite acceptable, particularly when a relatively quick prediction of flooding is needed such as for scenario analysis. The mass balance error of the simulation result is insignificant and this may be attributed to the finite volume scheme used for the solution of the model equations. In order to view the simulation results, the 2D Hydrodynamic Model creates a .plt file extension at the end of the simulation and this can be opened using a graphic visualizer such as Tecplot software (Tecplot $360^{\mathrm{TM}} 2008$ ). Figure 6 shows the flood extent map of the case study area and Fig. 7 shows the associated maximum flood. 
Table 1: Summary of the model result for the case study area

\section{Model results}

Total simulation time (h)

Model run-time (min)

Mass balance error (\%)

Total inundated area (ha)

Values

70

$7.6 \times 10^{-9}$ 1.13
Numerical configuration: For this case study, the computational domain area is estimated to be around 140 ha. This is triangulated into 176,180 cells. Other required files needed for the successful running of the $2 \mathrm{D}$ part of the coupled model were also produced during

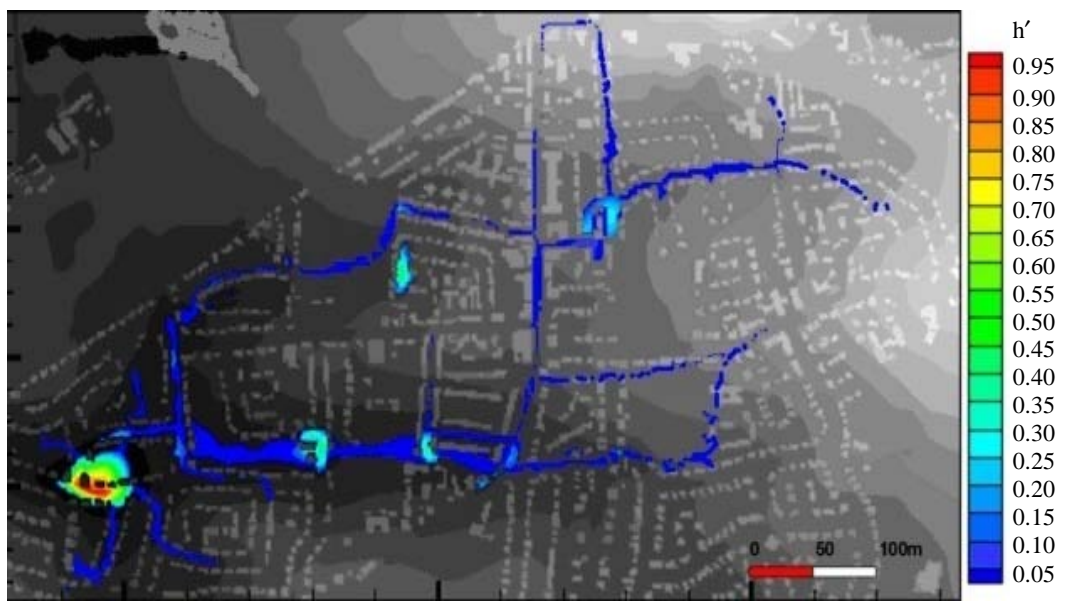

Fig. 6: Flood map of central model (West Garforth case study area) showing water depth $\mathrm{h}$ in meters

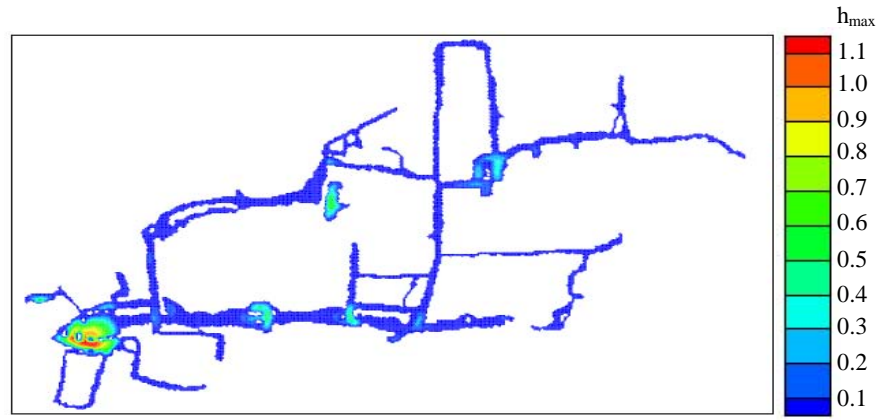

Fig. 7: Maximum flood option of the central model (West Garforth study area)

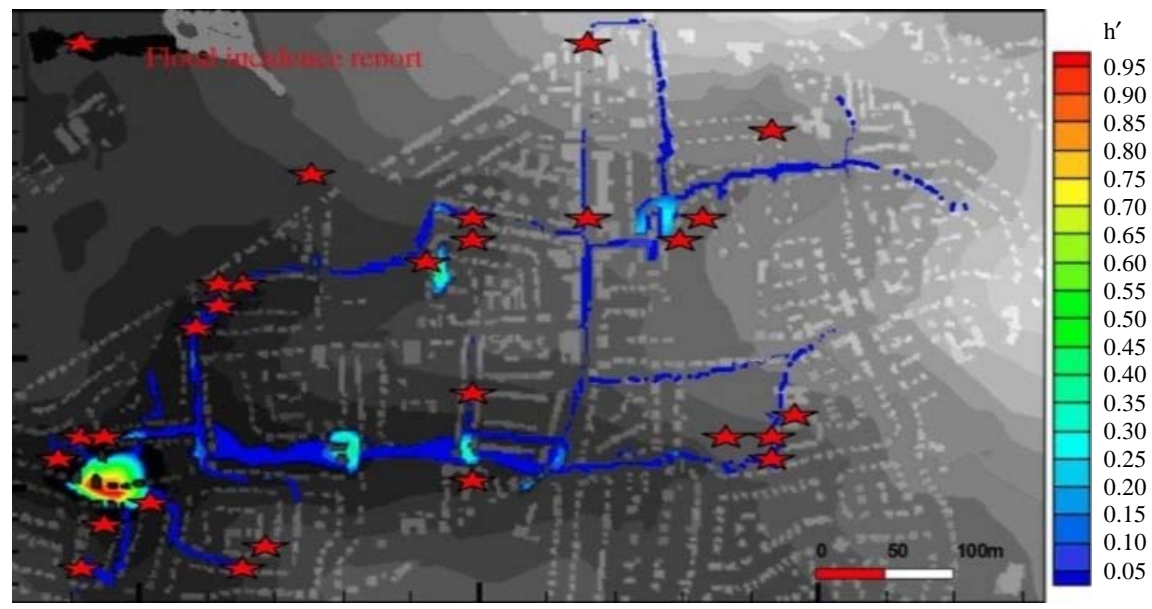

Fig. 8: Flooded nodes with flood incident reports at the case study area, West Garforth, UK 
triangulation. The time step is specified to be $0.05 \mathrm{sec}$ and the total number of time of simulation is 360,000 . This gives a total simulation time to be $5 \mathrm{~h}$. Furthermore, 60 monitoring zones for the purpose of reporting the flooding process every $5 \mathrm{~min}$ was set up in the model.

Model verification: Although, the developed 1D-2D Model is able to simulate the flood propagation and produces plausible results, the accuracy of the model very much depends on the availability of data and the quality of data used. Due to a lack of data for model verification, the flooded node locations were compared with the available flood incident reports and this is represented in the model layout (Fig. 8).

\section{CONCLUSION}

In this study, a coupled urban inundation model was developed for the purpose of meeting the requirement of simulating urban flooding for optimization studies, taking into consideration the possible interaction between the sewer network and surface system. This involved coupling the existing 1D-SWMM Model with the 2D Hydrodynamic Model, BreZo.

The key requirement for applying an inundation model for optimization purposes (e.g., evolutionary method like Genetic Algorithms) is its ability to perform the analysis swiftly with acceptable degree of accuracy. Many of the currently available off-the-shelf models are not able to achieve this computational economy for their original design was largely focused on manual analysis where the models are run several times for a given case so that the computational economy is not as critical as in optimization use. In the current study, researchers contributed towards this important niche.

The use of unstructured grids allows covering irregular geometries effectively and varying resolution from place to place as computations demand. The 1D-2D Model linking was effected only by mass transfer, ignoring momentum linkage. Again, this assumption leads to considerable simplicity and calculation economy and it is not an oversimplification for sewer overflow situations as opposed to river flooding or tidal surge.

The coupled model was used to examine the flooding events in Garforth (West Yorkshire, UK) for the purpose of determining the inundation extent, depth and velocity resulting from the surcharged water. It was found that the model is capable of handling efficiently flow conditions that may occur in the actual floodplain. The numerical prediction is also satisfactory for the case study and the simulation time is affordable on consumer hardware. Also, the model is stable with an insignificant mass balance error. Results of sensitivity analysis show that a better representation of flood map is achieved at lower mesh sizes but against higher computational costs. The use of larger computational mesh sizes reduces the computational cost but compromises accurate representation of the inundated area.

A major drawback of the case study was the inability to explicitly validate the inundation results which is not an uncommon situation in many small-scale flood problems. Only the results were examined against the incident reports that were available for the area which revealed that the general locations of flooding area as shown by model matches with indicated results. The inundation maps produced can serve as a decision support tool for authorities to arrive at flood management measures. The simulation results can also be of help to engineers in re-designing the capacities of the sewer systems at potential inundation areas. The application of the coupled model for optimization is presented elsewhere.

\section{ACKNOWLEDGEMENTS}

Researchers thanks the Netherland Government for providing him a fellowship award through Netherland Fellowship Program to pursue a master's degree at UNESCO-IHE. The researchers also acknowledge the contribution of Prof. Brett Sander of University of California for making the 2D Model available online.

\section{REFERENCES}

Begnudelli, L. and B.F. Sanders, 2006. Unstructured grid finite-volume algorithm for shallow-water flow and scalar transport with wetting and drying. J. Hydraulic Eng., 132: 371-384.

DEFRA, 2008. West garforth integrated urban drainage pilot study. Department for Environment, Food and Rural Affairs. Final Report.

FEH, 1999. Centre for Ecology and Hydrology. Natural Environmental Research Council, UK.

PWG, 2007. West garforth modeling studies (internal document, draft). Model Build and Calibration Determination of System Performance, West Garforth, UK.

Pathirana, A., S. Tsegaye, B. Gersonius and K. Vairavamoorthy, 2008. A simple 2-D inundation model for incorporating flood damage in urban drainage planning. Hydrol. Earth. Syst. Sci. Discuss., 5: 3061-3097.

Sanders, B.F., 2008. Integration of shallow water model with a local time step. J. Hyd. Res., 46: 466-475.

Shewchuk, J.R., 1996. Triangle: Engineering a 2D Quality Mesh Generator and Delaunay Triangulator, Applied Computational Geometry: Towards Geometric Engineering. Springer-Verlag, Berlin, pp: 203-222. 